\title{
COMPARISON OF ARMOURED SCALE SPRAY THRESHOLDS IN KIWIFRUIT
}

\author{
P.S. STEVENS ${ }^{1}$, C.E. MCKENNA ${ }^{2}$, R.H. BLANK ${ }^{3}$, \\ A.R. TOMKINS ${ }^{4}$ and D. STEVEN 5
}

\author{
HortResearch, 'PB 92 169, Auckland; \\ ${ }^{2} 412$ No 1 Rd, Te Puke; \\ ${ }^{3} \mathrm{~PB}$ 9003, Whangarei; \\ ${ }^{4} P B$ 3123, Hamilton; \\ ${ }^{5}$ IPM Research Ltd, PO Box 36 012, Northcote
}

\begin{abstract}
The potential of a pest monitoring system to reduce the number of spray applications while still maintaining control of armoured scale was assessed. Armoured scale were monitored on leaves within a block and sprays were only applied if a predetermined percentage of leaves were infested with live armoured scale. The thresholds compared were either 4 or $8 \%$ of leaves infested. The number of sprays applied and armoured scale infestation at harvest were recorded. All blocks managed using the monitoring system received a reduced number of sprays compared with a calendar spray programme, although an increase in armoured scale on fruit was recorded. Increases in armoured scale levels on fruit under reduced spray programmes were generally economically insignificant.

Keywords: pest monitoring, spray thresholds, armoured scale, kiwifruit
\end{abstract}

\section{INTRODUCTION}

Three species of armoured scale insects have been recorded infesting kiwifruit leaves, wood and fruit. The three species are greedy scale (Hemiberlesia rapax), latania scale (H. lataniae) and oleander scale (Aspidiotus nerii) (Berry et al. 1989). The armoured scale cause only minor cosmetic damage to fruit but their presence can cause market access difficulties.

In the past, the key pests of kiwifruit (armoured scale and leafrollers) were controlled by a calendar spray programme of broad spectrum insecticides. However, pest control in kiwifruit has recently been transformed by the introduction of a first-stage Integrated Pest Management system commonly known as Kiwigreen (Steven et al. 1994). Monitoring systems for armoured scale and leafroller have been developed and are being used by pest scouts to determine the need for insecticide application. Orchards are monitored for pests and sprays recommended on a block by block basis. Broad-spectrum insecticides, e.g. diazinon, are no longer permitted after approximately the end of January, and armoured scale and leafroller control during the later half of the season relies on sprays of mineral oil or Bacillus thuringiensis (Bt) products respectively.

Before wider industry uptake, the armoured scale monitoring system was developed and validated over several years of trials. The system involves determining the number of leaves in a sample with live armoured scale and using this as an indication of fruit infestation. The disadvantage of this leaf sampling system is that armoured scale levels on leaves may not always provide a reliable estimate of the potential level of fruit infestation (Blanket al. 1994). An alternative approach would be to monitor armoured scale levels on fruit, but this would be impractical given the high cost of collecting repeated fruit samples.

Initial trials compared several spray thresholds, ranging from 1 to $16 \%$ of leaves infested with live armoured scale (unpublished data). Once the feasibility and potential 
of the armoured scale monitoring system was established, more extensive tests of either a 4 or $8 \%$ threshold were carried out. This paper reports on some of the validation trials comparing the levels of fruit infestation on blocks managed with either a 4 or $8 \%$ spray threshold.

\section{METHODS}

In the 1989-90 and 1990-91 seasons, 18 and 20 orchardists respectively, participated in the trial. On most orchards, the efficacy of a standard calendar spray programme was compared with at least two blocks managed using spray thresholds (Table 1). On two occasions in 1989-90, no control block was available. Orchards were located in the Northland, Waikato, Bay of Plenty, Gisborne and Nelson regions. A total of 52 and 69 blocks were used in the 1989-90 and 1990-91 seasons, respectively.

\section{Armoured scale monitoring system}

Approximately 100 mature kiwifruit leaves were collected from each block at about three weekly intervals from late January to harvest. Equal numbers of leaves were collected from each row within a block and were examined under a microscope for the presence of live armoured scale. A leaf was recorded as infested if any live scale were observed. To distinguish between live and dead scale, the armoured scale cap was lifted and the colour and fluid content of the scale body was examined. A live scale body is bright yellow and full of fluid, while dead scale bodies are darker and dehydrated. For each leaf sample the percentage of leaves infested with live armoured scale was calculated.

\section{Spray programme and thresholds}

All blocks received the growers' choice of winter treatments and post-flowering spray programmes. All blocks received two post-flowering insecticides as this is the critical time for leafroller control (Stevens et al. 1995). The timing and choice of the active ingredient used for the two post-blossom sprays varied between growers. The range of materials included diazinon, phosmet and chlorpyrifos. A few days before the third spray was due to be applied, a leaf sample was picked and sent to participating science centres for armoured scale assessment. The timing of the first leaf sample ranged from early January to early February. Sprays for each block were recommended on the basis of a pre-selected spray threshold. Blocks were managed using either a 4 or $8 \%$ spray threshold or in the case of the control blocks, sprays were applied on a calendar basis, irrespective of the level of live scale found on the leaves.

\section{Armoured scale infestation on fruit}

A sample of at least 300 fruit was collected from each block at harvest. Fruit were examined microscopically for the presence of armoured scale (live and dead).

\section{Statistical analysis}

Treatments were compared using ANOVA on angular transformed percentages, although untransformed percentages are presented in tables. Any significant differences were analysed using Fishers Least Significant Differences (LSD). All analysis was carried out using the statistics package SAS (SAS Institute Inc. 1985).

\section{Early season armoured scale populations}

\section{RESULTS AND DISCUSSION}

Despite the variation in early season spray programmes, all blocks had similar levels of armoured scale infestation on leaves at the start of the sampling period. There were no significant differences between blocks or seasons, in the percentage of leaves infested with live scale at the time of the first leaf sample (Table 1). A mean of $4.1 \%$ of leaves (SE $=0.9, \mathrm{n}=52$ ) were infested in 1989-90 compared to a mean of $8.1 \%$ $(\mathrm{SE}=1.9, \mathrm{n}=69)$ in the 1990-91 season. The higher mean leaf infestation in the second season was influenced by the inclusion of some blocks with extremely high levels of armoured scale (e.g. one block had $88 \%$ of leaves infested with live scale at the time of the first leaf sample). In both seasons the median percentage of leaves infested with live scale was very similar (1.9 and 2.0\% for 1989-90 and 1990-91, respectively).

TABLE 1: Mean percentage $( \pm$ SE) of kiwifruit leaves infested with live armoured scale at the time of the first leaf sample after two post-blossom sprays. 


\begin{tabular}{|c|c|c|c|}
\hline \multirow[t]{2}{*}{ Season } & \multicolumn{3}{|c|}{ Spray threshold } \\
\hline & Control & $4 \%$ & $8 \%$ \\
\hline $1989-90$ & $\begin{array}{c}4.9 \pm 2.2 \mathrm{a}^{1} \\
(\mathrm{n}=16)\end{array}$ & $\begin{array}{l}4.1 \pm 1.5 a \\
\quad(n=18)\end{array}$ & $\begin{array}{c}3.2 \pm 1.2 \mathrm{a} \\
\quad(\mathrm{n}=18)\end{array}$ \\
\hline 1990-91 & $\begin{array}{c}6.6 \pm 2.6 \mathrm{a} \\
(\mathrm{n}=23)\end{array}$ & $\begin{array}{c}7.6 \pm 3.0 \mathrm{a} \\
(\mathrm{n}=23)\end{array}$ & $\begin{array}{c}10.1 \pm 4.2 \mathrm{a} \\
(\mathrm{n}=23)\end{array}$ \\
\hline
\end{tabular}

${ }^{1}$ Numbers within a row followed by the same letter are not significantly different $(\mathrm{P}>0.05)$

\section{Number of sprays applied through season}

Using the armoured scale monitoring system significantly reduced the number of insecticide applications on all blocks, regardless of the threshold level (Table 2). Increasing the spray threshold from 4 to $8 \%$ did not further reduce the mean number of sprays.

Most blocks managed with a spray threshold had a reduced number of sprays compared to the controls ( $83 \%$ of the $4 \%$ blocks and $78 \%$ of the $8 \%$ blocks in $1989-90$; $83 \%$ of the $4 \%$ blocks and $87 \%$ of the $8 \%$ blocks in 1990-91). A few blocks never exceeded the spray threshold at any sampling occasion through the season, so no additional sprays were applied ( $6 \%$ of the $4 \%$ blocks and $22 \%$ of the $8 \%$ blocks in 1989 $90 ; 35 \%$ of the $4 \%$ blocks and $22 \%$ of the $8 \%$ blocks in $1990-91$ ).

TABLE 2: Mean number $( \pm \mathrm{SE})$ of sprays applied to kiwifruit through the season, including two automatically applied post-blossom sprays.

\begin{tabular}{|c|c|c|c|}
\hline Season & Control & $\begin{array}{c}\text { Spray threshold } \\
4 \%\end{array}$ & $8 \%$ \\
\hline $1989-90$ & $\begin{array}{c}6.7 \pm 0.2 \mathrm{a}^{1} \\
{[\mathrm{range}=6-8]} \\
(\mathrm{n}=16)\end{array}$ & $\begin{array}{c}4.3 \pm 0.3 \mathrm{~b} \\
{[\text { range }=2-6]} \\
(\mathrm{n}=18)\end{array}$ & $\begin{array}{c}3.6 \pm 0.3 \mathrm{~b} \\
{[\text { range }=2-6]} \\
(\mathrm{n}=18)\end{array}$ \\
\hline $1990-91$ & $\begin{array}{c}6.3 \pm 0.3 \mathrm{a} \\
{[\mathrm{range}=3-10]} \\
(\mathrm{n}=23)\end{array}$ & $\begin{array}{c}4.1 \pm 0.5 \mathrm{~b} \\
{[\text { range }=2-10]} \\
(\mathrm{n}=23)\end{array}$ & $\begin{array}{c}3.8 \pm 0.4 \mathrm{~b} \\
{[\mathrm{range}=2-10]} \\
(\mathrm{n}=23)\end{array}$ \\
\hline
\end{tabular}

${ }^{1}$ Numbers within a row followed by the same letter are not significantly different $(\mathrm{P}>0.05)$

\section{Scale infestation on fruit at harvest}

In the 1989-90 season, blocks managed with either the 4 or $8 \%$ spray thresholds had significantly higher levels of fruit infested with armoured scale compared to the control (Table 3).

In 1990-91, blocks managed with an 8\% spray threshold had more scale-infested fruit compared to the control; however, blocks managed with the $4 \%$ threshold did not have significantly more infested fruit. In both seasons, there was no significant difference in scale control achieved when blocks were managed using either a 4 or $8 \%$ spray threshold. While the observed increase in fruit infestation relative to the controls was statistically significant, it was not necessarily economically significant. It must be remembered that these measurements of scale infestation were obtained by detailed microscopic examination and a commercial packhouse would not usually detect armoured scale with the same degree of sensitivity. For example, lines of fruit with up to 5\% armoured scale (determined microscopically) have successfully met export grade standards (Stevens et al. 1993).

TABLE 3: Mean percentage $( \pm S E)$ of kiwifruit fruit infested with armoured scale at harvest. 


\begin{tabular}{cccc} 
& Control & $4 \%$ & $8 \%$ \\
\hline $1989-90$ & $\begin{array}{c}0.5 \pm 0.2 \mathrm{a}^{1} \\
(\mathrm{n}=16)\end{array}$ & $\begin{array}{c}1.0 \pm 0.2 \mathrm{~b} \\
(\mathrm{n}=18)\end{array}$ & $\begin{array}{c}1.4 \pm 0.3 \mathrm{~b} \\
(\mathrm{n}=18)\end{array}$ \\
$1990-91$ & $\begin{array}{c}0.7 \pm 0.3 \mathrm{a} \\
(\mathrm{n}=23)\end{array}$ & $\begin{array}{c}0.9 \pm 0.3 \mathrm{ab} \\
(\mathrm{n}=23)\end{array}$ & $\begin{array}{c}1.5 \pm 0.3 \mathrm{~b} \\
(\mathrm{n}=23)\end{array}$ \\
\hline
\end{tabular}

${ }^{1}$ Numbers within a row followed by the same letter are not significantly different $(\mathrm{P}>0.05)$

When Kiwigreen was initiated, a spray threshold of $4 \%$ of leaves infested with live armoured scale was chosen as the industry standard. The level of $4 \%$ scale infestation was an arbitrary figure which aimed to reduce sprays while still maintaining acceptable control of armoured scale. It was recommended as a conservative threshold, so that the risk of fruit infestation was minimised. In practice, the armoured scale monitoring system and a $4 \%$ spray threshold has proved to be a very useful tool for managing armoured scale with a reduced number of sprays.

Because of the risk of late season phytotoxic damage from oil sprays (McKennaet al. 1995), there has been some interest in increasing the spray threshold at the end of the season. There is currently no information on the reliability and precision of individual leaf samples, and while this information is unknown, the sense of comparing and distinguishing between scale thresholds of 4 and $8 \%$ is questionable. The monitoring system is possibly acting as a very crude sieve, and any threshold in the range tested may give similar results. However, the results reported in this paper suggest that the armoured scale threshold could be lifted to $8 \%$, without a significant corresponding increase in the percentage of fruit infested with armoured scale at harvest. Any slight increase in armoured scale infestation on fruit is not likely to be economically significant, and this must be weighed up against the risk of late season oil phytotoxicity.

\section{CONCLUSION}

The use of an armoured scale monitoring system effectively reduced the number of sprays applied to kiwifruit, irrespective of whether a $4 \%$ or $8 \%$ spray threshold was used. Slightly higher levels of scale were found on fruit which received fewer sprays, although any increases were not economically significant. There were no significant differences in armoured scale control in blocks managed with either a $4 \%$ or $8 \%$ threshold.

\section{ACKNOWLEDGEMENTS}

The authors would like to thank the many growers who assisted with this trial. We would also like to thank K. Froud, M. Olson, J. Kelly, B. Tapper, C. Thomson and D. Wilson for technical assistance. This work was funded by the New Zealand Kiwifruit Marketing Board.

\section{REFERENCES}

Blank, R.H., Gill, G.S.C. and Olson, M.H., 1994. Relationship between armoured scale infestations on kiwifruit leaves and fruit. Proc. 47th N.Z. Plant Prot. Conf.: 304309.

Berry, J.A., Morales, C.F., Hill, M.G., Lofroth, B.J. and Allan, D.J., 1989. The incidence of three diaspid scales on kiwifruit in New Zealand.Proc. 42nd N.Z. Weed and Pest Control Conf.: 182-186.

McKenna, C.E., Stevens, P.S. and Steven, D., 1995. Phytotoxicity to kiwifruit from sprays of mineral oil.Acta Hort.: (in press)..

SAS Institute Inc., 1985. SAS Users Guide: Basics, Version 5 Edition. Cary, NC: SAS Institute Inc. 1290 p.

Steven, D., Tomkins, A.R., Blank, R.H. and Charles, J.G., 1994. A first-stage integrated pest management system for kiwifruit.Proc. Brighton Crop Prot. Conf. Vol. 1: 135142.

Stevens, P.S., McKenna, C.E. and Steven, D., 1995. The timing of lepidopteran damage 
to kiwifruit. Proc. 48th N.Z. Plant Prot. Conf.: 130-134.

Stevens, P.S., Steven, D., Malcolm, C. and Holland, P.T., 1993. Reducing pesticide residues on kiwifruit. Proc. 46th N.Z. Plant Prot. Conf.: 62-66. 